\title{
Article \\ Numerical Investigation on the Evolution of Thin Liquid Layer and Dynamic Behavior of an Electro-Thermal Drilling Probe during Close-Contact Heat Transfer
}

\author{
Chan Ho Jeong ${ }^{1}$, Kwangu Kang ${ }^{2}{ }^{\circledR}$, Ui-Joon Park ${ }^{1}$, Hyung Ju Lee ${ }^{1}$, Hong Seok Kim ${ }^{1}$, Jin-Yeong Park ${ }^{3}$ \\ and Seong Hyuk Lee ${ }^{1,4, *}$ \\ 1 School of Mechanical Engineering, Chung-Ang University, Seoul 06974, Korea; chjwjeong@naver.com (C.H.J.); \\ ujsplendid8@naver.com (U.-J.P.); thyu12@naver.com (H.J.L.); khseok94@naver.com (H.S.K.) \\ 2 Offshore Industries R \& BD Center, Korea Research Institute of Ships and Ocean Engineering, \\ Geoje 53201, Korea; kgkang@kriso.re.kr \\ 3 Ocean System Engineering Research Division, Korea Research Institute of Ships and Ocean Engineering, \\ Daejeon 34103, Korea; jinyeong96@kriso.re.kr \\ 4 Department of Intelligent Energy and Industry, Chung-Ang University, Seoul 06974, Korea \\ * Correspondence: shlee89@cau.ac.kr; Tel.: +82-2-820-5254
}

check for updates

Citation: Jeong, C.H.; Kang, K.; Park, U.-J.; Lee, H.J.; Kim, H.S.; Park, J.-Y.; Lee, S.H. Numerical Investigation on the Evolution of Thin Liquid Layer and Dynamic Behavior of an Electro-Thermal Drilling Probe during Close-Contact Heat Transfer. Appl. Sci. 2021, 11, 3443. https:// doi.org/10.3390/app11083443

Received: 20 February 2021

Accepted: 9 April 2021

Published: 12 April 2021

Publisher's Note: MDPI stays neutral with regard to jurisdictional claims in published maps and institutional affiliations.

Copyright: (c) 2021 by the authors. Licensee MDPI, Basel, Switzerland. This article is an open access article distributed under the terms and conditions of the Creative Commons Attribution (CC BY) license (https:/ / creativecommons.org/licenses/by/ $4.0 /)$.

\begin{abstract}
This study investigates the transient behavior of an electro-thermal drilling probe (ETDP) during a close-contact melting process within a glacier. In particular, the present work analyzes the effect of the tip temperature on the formation of molten thin liquid films and the subsequent rate of penetration (ROP) through numerical simulation. We used the commercial code of ANSYS Fluent (v.17.2) to solve the Reynolds-averaged Navier-Stokes equation, together with an energy equation considering the solidification and melting model. The ROP of the drilling probe is determined based on the energy balance between the heating power and melting rate of ice. As the results, the ETDP penetrates the ice through a close-contact melting process. The molten liquid layer with less than $1 \mathrm{~mm}$ of thickness forms near the heated probe tip. In addition, the ROP increases with the heated temperature of the probe tip.
\end{abstract}

Keywords: electro-thermal drilling probe (ETDP); close-contact melting (CCM); computational fluid dynamics (CFD); rate of penetration (ROP); thermal characteristics

\section{Introduction}

Glaciers and ice in polar regions have essential information about the past as well as recent geological history and climate change [1]. An unexplored subglacial lake, which is a lake formed under a glacier, attracts researchers from various fields, such as biology, astrobiology, and biochemistry [1-3]. After discovering unknown life and information in the Vostok glacier in Antarctica, a great deal of research has been conducted to reach the glacier and obtain microbial samples. Therefore, it is essential to develop polar exploration technology (i.e., drilling technology), facilitating quick penetration toward subglacial lakes without contamination in an ecosystem of the polar regions.

There are various conventional drilling techniques, such as wire-line drilling, hotwater drilling, and coiled-tube drilling that can penetrate the ice and reach a subglacial lake [4]. However, it is reported that such a conventional drilling method can cause contamination in both the polar regions and in retrieved samples [5,6]. An electro-thermal drilling probe (ETDP) is a promising way to facilitate the exploration of the subglacial lake without contamination and has been widely used to penetrate the glacier [7-9]. A heated probe tip is attached in the head of the ETDP, as shown in Figure 1. The ice which is in contact with the heated probe tip starts to melt and forms a thin liquid film [10-12]. Subsequently, the ETDP pushes the thin liquid film due to its weight and can slowly move downward through the close-contact melting process. 


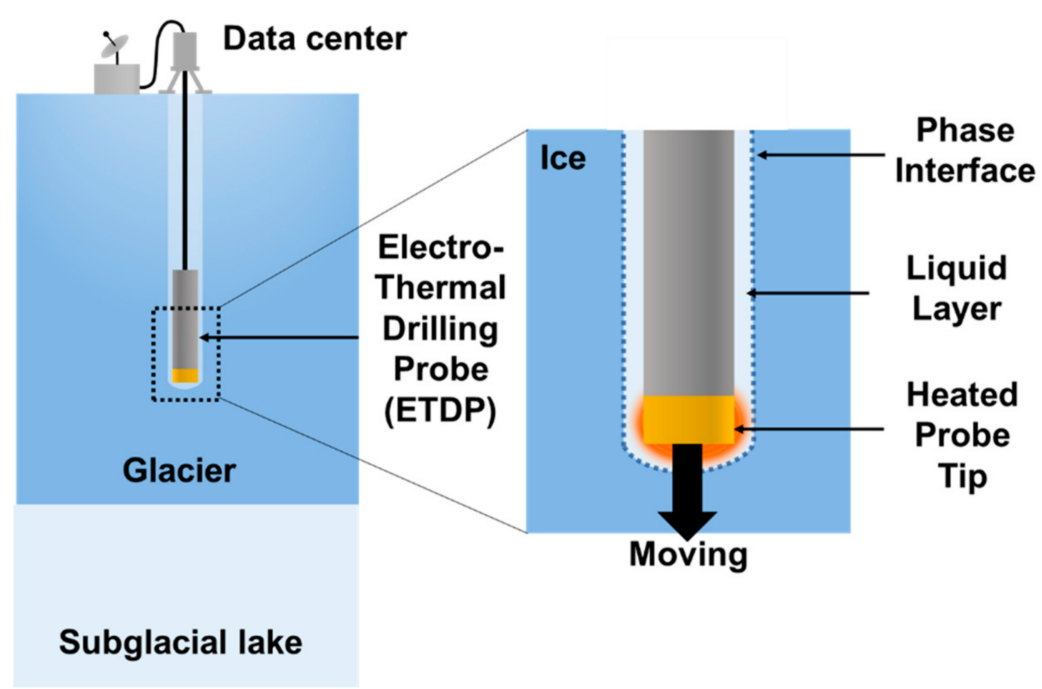

Figure 1. Schematic of the drilling process of electro-thermal drilling probe (ETDP).

The rate of penetration (ROP), which indicates the speed at which the heated probe tip deepens the borehole, has been one of the key parameters in designing the shape and operating conditions of an ETDP [12-15]. Many researchers have analyzed the effect of factors, such as operating conditions and melting-tip shape, on the ROP. Shreve et al. [12] found that the ROP increased with heating power and the cross-sectional area of heated probe tip owing to a faster phase change with the increase in heating power. Talalay et al. [13] showed that a copper heated probe tip could penetrate ice faster because of its higher thermal conductivity. In addition, they conducted a parametric study to investigate the effect of the heated probe tip shape on the ROP. From the results, the heated probe tip with a $60^{\circ}$ cone shape shows the highest ROP. They also found that the ROP increased with the weight of ETDP because heavier a ETDP can squeeze the molten liquid layer more strongly and move faster. Treffer et al. [15] provided several lab-scale experimental results showing that an ETDP with a spherical shape penetrates an ice-chamber faster with a higher heating power. The simple model was suggested to predict ROP based on the required heating power for melting ice. They over-estimated the ROP by about $30 \%$ compared to the experimental results. Suto et al. [14] studied the effects of the shape and material of the drill head and heater temperature on the rate of penetration via lab-scale experiments. They also estimated the total required thermal energy considering the thermal loss with various conditions through a one-dimension heat conduction problem. From the experimental results, a conical shape showed a higher ROP than a flat shape due to the large contact area with ice.

The studies mentioned above broadly analyzed the effects of design factors (shape and operating conditions) of ETDPs on the ROP. Unfortunately, there is a lack of information to understand the underlying physics of the drilling process considering the close-contact melting characteristics of ETDP. The heated probe tip melts the ice and forms a thin liquid layer [12]. The ETDP pushes the molten liquid layer and can move in a downward direction. The thin liquid layer plays a role in thermal resistance and influences heat transfer characteristics during the melting process. However, such close-contact melting characteristics of ETDP are not easily directly measured. Indeed, computational fluid dynamics (CFD) is a promising way to investigate various multi-physics problems in unsteady and quasi-steady states [16-19] and to obtain useful information which would not be easily measured directly. Therefore, the present study proposes a numerical approach to mimic the drilling process considering the close-contact melting phenomenon. This work aims to analyze the effects of the heated probe tip temperature on the formation of molten liquid layers and the subsequent ROP inside an ice region. In particular, we characterize the transient behavior of molten thin liquid layers near the heated electro-thermal drilling probe (ETDP), which is difficult to measure directly. 


\section{CFD Simulations}

\subsection{Governing Equations}

The present study analyzes the transient behavior of thin liquid film formation near a heated probe tip. We used the commercial code of ANSYS Fluent (v.17.2) to solve the conservation equations of mass and momentum as follows:

$$
\begin{gathered}
\frac{\partial \rho}{\partial t}+\frac{\partial(\rho \vec{v})}{\partial x}=0 \\
\frac{\partial}{\partial t}(\rho \vec{v})+\nabla \cdot(\rho \vec{v} \vec{v})=-\nabla p+\nabla \cdot(\widetilde{\tau})+\rho \vec{g}
\end{gathered}
$$

where $\rho$ is the density, $v$ is the velocity vector, $p$ is the pressure, $\tau$ denotes the stress tensor, and $g$ is the gravitational acceleration. The enthalpy-based energy equation considering the solidification and melting model is as follows [20-23]:

$$
\frac{\partial}{\partial t}(\rho H)+\nabla \cdot(\rho \vec{v} H)=\nabla \cdot(k \nabla H)
$$

where $H$ indicates the enthalpy and $k$ is the thermal conductivity. The enthalpy, $H$, is defined as the sum of the sensible enthalpy, $h$, and the latent enthalpy, $\Delta H$, as follows:

$$
\begin{gathered}
H=h+\Delta H \\
h=h_{r e f}+\int_{T_{r e f}}^{T} c_{p} d T \\
\Delta H=\beta L
\end{gathered}
$$

where $h_{r e f}$ is reference enthalpy, $T_{r e f}$ is reference temperature, $c_{p}$ is the specific heat, and $L$ is the latent heat. The liquid fraction, $\beta$, is estimated by:

$$
\beta=\left\{\begin{array}{cc}
0 & T<T_{S} \\
1 & T>T_{L} \\
\left(T-T_{S}\right) /\left(T_{L}-T_{S}\right) & T_{S}<T<T_{L}
\end{array}\right.
$$

where $T_{S}$ denotes solidus temperature at which the solidification begins, and $T_{L}$ represents liquidus temperature at which the melting begins. However, Equation (7) can be used for the case where the values of $T_{S}$ and $T_{L}$ are different (e.g., alloys and multiple substances). In the case of a pure substance (e.g., water/ice), $T_{S}$ is equal to $T_{L}$. Therefore, $\beta$ should be expressed based on the enthalpy as follows:

$$
\beta=\left\{\begin{array}{cc}
0 & H<H_{S} \\
1 & H>H_{L} \\
\left(H-H_{S}\right) /\left(H_{L}-H_{S}\right) & H_{S}<H<H_{L}
\end{array}\right.
$$

where $H_{S}$ indicates enthalpy of the solid at which the phase change begins, and $H_{L}$ represents enthalpy of the liquid. The liquid fraction, $\beta$, is zero at the solid phase where the temperature is below $273 \mathrm{~K}$. When the temperature of the solid phase increases to $273 \mathrm{~K}$, the enthalpy of the material, $H$, starts to increase from $H_{S}$ to $H_{L}$. The liquid fraction, $\beta$, changes with corresponding enthalpy, $H$.

\subsection{Numerical Details}

Figure 2 shows that the 2D axisymmetric computational domain has a length of $360 \mathrm{~mm}$ and width of $75 \mathrm{~mm}$. We determined the geometry of the cylindrical ETDP with a flat shaped heated probe tip by referring to a previous experimental study [14]. The ETDP 
with a height of $160 \mathrm{~mm}$ and radius of $25 \mathrm{~mm}$ was placed within the ice region, as shown in Figure 2. The temperature of the ice boundary, $T_{i c e}$, was set as $253 \mathrm{~K}$. The top and side temperatures of ETDP, $T_{\text {top }}$ and $T_{\text {side, }}$, were determined as $323 \mathrm{~K}$. The present study changed the heated probe tip temperature, $T_{\text {tip }}$, from 348 to $368 \mathrm{~K}$ to analyze the influence of the heated probe tip temperature on thin film formation near the ETDP and the corresponding ROP. A grid size of $0.5 \mathrm{~mm}$ was selected by the grid convergence tests, and the total grid number was 92,150. The present work used the pressure-implicit with splitting of operators (PISO) algorithm, which is widely used for solving solidification and melting problems to couple the pressure with the velocity [24-26]. The time-step was adaptively selected in the range from $10^{-5}$ to $10^{-3} \mathrm{~s}$ to reduce the computational time. Convergence criteria of the solution were set as the residual value of $10^{-3}$ for continuity, $10^{-4}$ for momentum, and $10^{-8}$ for energy.

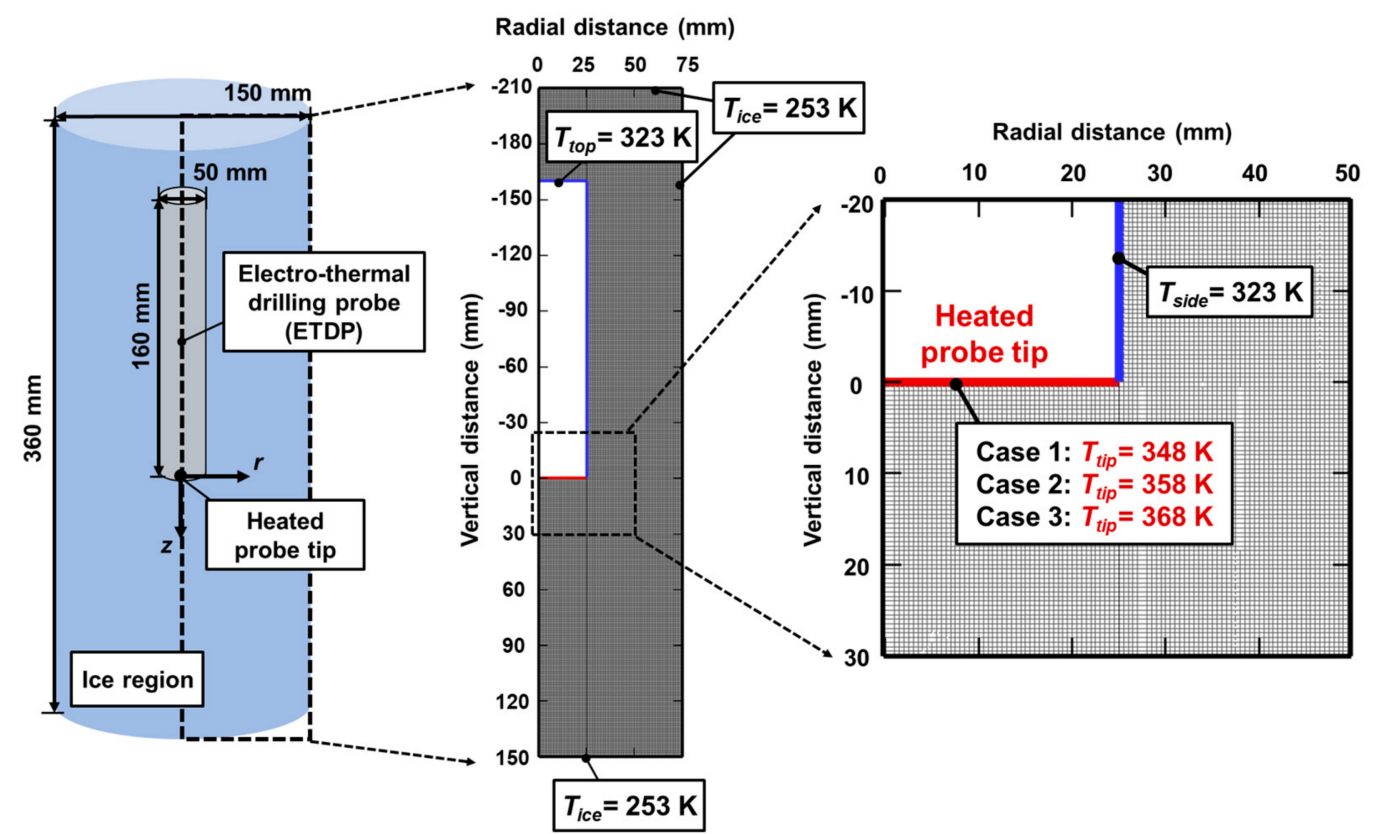

Figure 2. The schematic of the computational domain and corresponding boundary conditions.

\subsection{Dynamic Motion of ETDP}

The present study provides a numerical approach to mimic penetration movement of ETDP with the use of the dynamic meshing method. The ROP of ETDP is determined based on the simple energy balance between the heating power and latent heat of melting ice, as follows:

$$
P=\pi R^{2} \frac{d \delta}{d t} \rho_{i c e} L
$$

where $P$ represents heating power transmitted from the heated probe tip of ETDP to the ice, $R$ is the radius of the heated probe tip, $\delta$ is the thickness of the molten liquid layer, $\rho_{\text {ice }}$ is the density of ice, and $L$ is latent heat. By assuming that the melting rate of ice, $d \delta / d t$, is equal to the velocity of the ETDP, $v$, Equation (9) can be expressed as follows:

$$
\frac{d \delta}{d t} \sim v=\frac{P}{\pi R^{2} \rho_{\text {ice }} L}
$$

Finally, we calculate the ROP by using the user defined function (UDF) based on Equation (10). 


\subsection{Validation of the Numerical Method}

Unfortunately, there is a lack of information on experiments to evaluate the proposed numerical method. As an alternative, additional CFD simulations were carried out to assess the numerical method established in the present study by comparing with previous report results [13]. Talalay et al. [13] reported the ROP of a heated cylindrical ETDP with flat shape heated probe tip with different heating power. We carried out additional CFD simulations by mimicking the ETDP geometry used in Talalay's experiments. The present study compares the predicted ROP using the proposed numerical method with the experimental results [13]. From the comparison, the order of predicted ROP has a similar value with the experimental results, as summarized in Table 1. The present model overestimates the ROP with an $18 \%$ maximum discrepancy at the heating power of $480 \mathrm{~W}$. Considering the experimental uncertainty, the current prediction of the ROP would be acceptable, but further work should be done to get a more accurate solution.

Table 1. Comparison of the predicted results of rate of penetration (ROP) with the experimental results [13].

\begin{tabular}{cccc}
\hline Heating Power & Rate of Penetration (Experiment Result) & Rate of Penetration (Prediction Model Result) & Error \\
\hline $240 \mathrm{~W}$ & $0.380 \mathrm{~mm} / \mathrm{s}$ & $0.329 \mathrm{~mm} / \mathrm{s}$ & $13.4 \%$ \\
$300 \mathrm{~W}$ & $0.458 \mathrm{~mm} / \mathrm{s}$ & $0.411 \mathrm{~mm} / \mathrm{s}$ & $10.2 \%$ \\
$360 \mathrm{~W}$ & $0.508 \mathrm{~mm} / \mathrm{s}$ & $0.494 \mathrm{~mm} / \mathrm{s}$ & $2.7 \%$ \\
$480 \mathrm{~W}$ & $0.55 \mathrm{~mm} / \mathrm{s}$ & $0.65 \mathrm{~mm} / \mathrm{s}$ & $18 \%$ \\
\hline
\end{tabular}

\section{Result and Discussion}

Firstly, we assumed the initial condition under which a molten liquid layer of $1 \mathrm{~mm}$ thickness is formed at $t=0 \mathrm{~s}$ around the ETDP by referring to previous literature [11]. Figure $3 \mathrm{a}-\mathrm{c}$ shows the temperature for the case of $T_{\text {tip }}=368 \mathrm{~K}$ over time. The heat is diffused from the heated probe tip toward the ice region. The highest temperature can be found near the ETDP. The enlarged temperature and enthalpy fields are highlighted by a green box and are illustrated in Figure 3d,e, respectively.

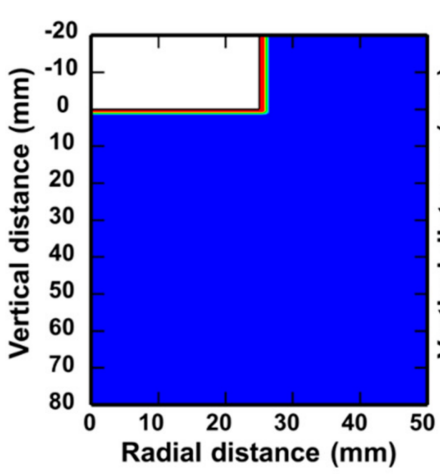

(a) $t=0 \mathrm{~s}$

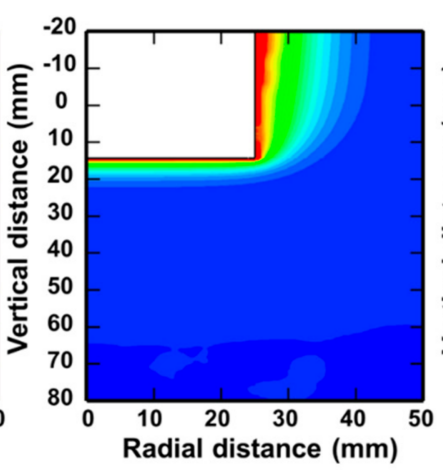

(b) $t=30 \mathrm{~s}$

Temperature (K)

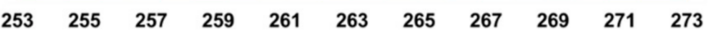

(c) $t=60 \mathrm{~s}$

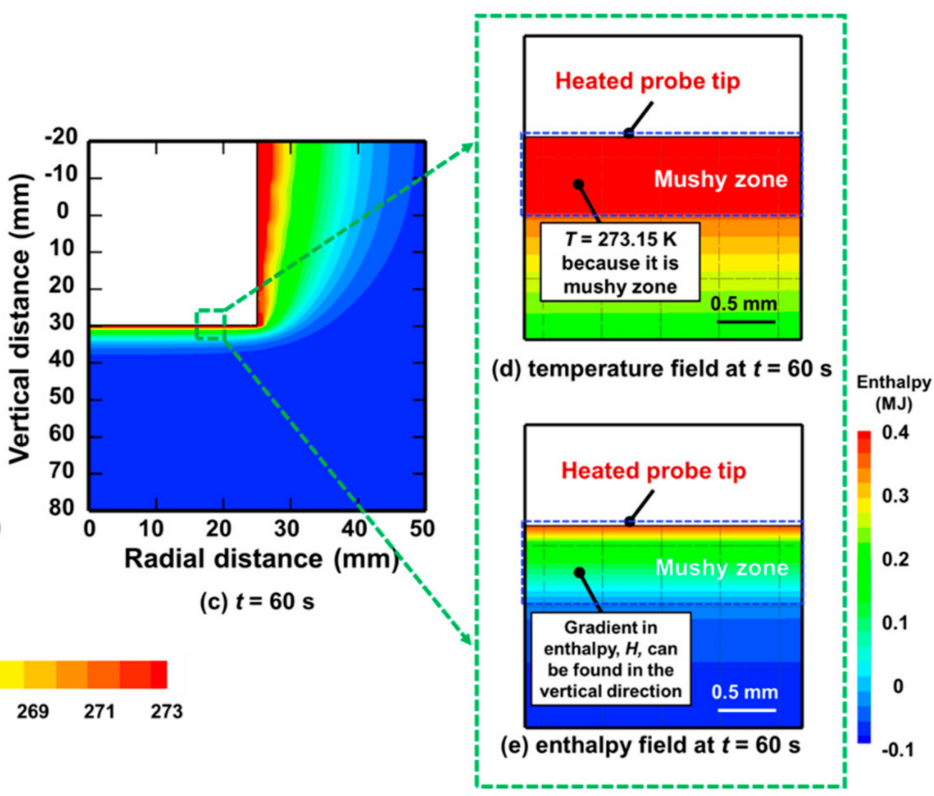

Figure 3. The temperature distribution around the electro-thermal drilling probe (ETDP) for the case of heated probe tip temperature of $T_{\text {tip }}=368 \mathrm{~K}$ at time (a) $t=0 \mathrm{~s},(\mathbf{b}) t=30 \mathrm{~s}$, and (c) $t=60 \mathrm{~s}$. The enlarged fields of (d) temperature and (e) enthalpy within the green dotted box. 
Interestingly, the ice that contacted with the heated probe tip remained at $273.15 \mathrm{~K}$ since it is the mushy zone (highlighted by a blue dotted box) where the phase change occurs. Although the mushy zone has a constant temperature of $273.15 \mathrm{~K}$, as shown in Figure $3 \mathrm{~d}$, it is worth noting that enthalpy within the mushy zone presents a gradient toward the vertical direction, as shown in Figure 3e. This means that when the temperature of ice reaches $273.15 \mathrm{~K}$ (melting temperature), enthalpy begins to increase with a fixed temperature $(T=273.15 \mathrm{~K})$ and the corresponding liquid fraction from Equation (8) also increases during the melting process.

Figure $4 \mathrm{a}-\mathrm{c}$ shows the liquid fraction fields for the case of a heated probe tip temperature, $T_{\text {tip }}$, of $368 \mathrm{~K}$ over time. As mentioned above, the ice region, where the temperature reaches $273.15 \mathrm{~K}$, becomes a mushy zone where the liquid fraction is between 0 and 1 . The liquid fraction inside the green dotted box in Figure $4 \mathrm{~d}$. Not surprisingly, it shows very similar distribution with the enthalpy distribution shown in Figure 3e. The thin liquid layer is formed near the heated probe tip. This implies that ETDP can move in a downward direction by pushing and squeezing the liquid layer, as shown in Figure $4 \mathrm{e}$.

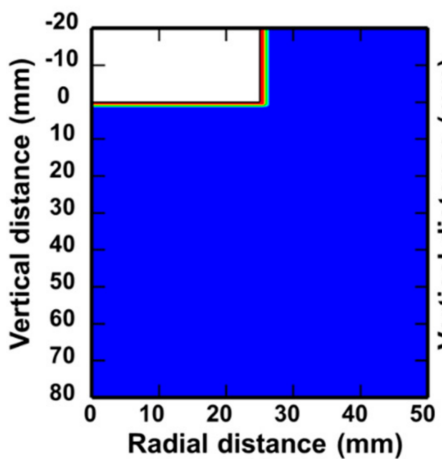

(a) $t=0 \mathrm{~s}$

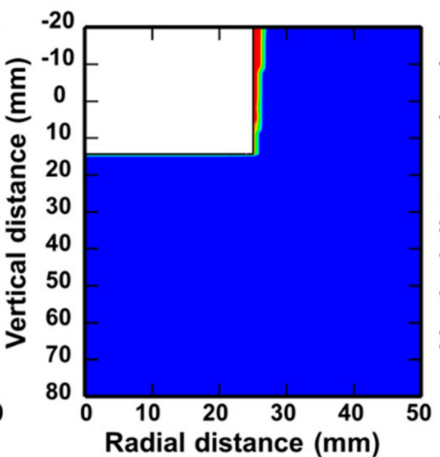

(b) $t=30 \mathrm{~s}$

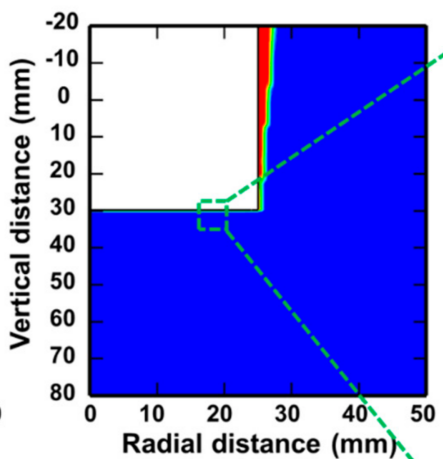

(c) $t=60 \mathrm{~s}$

Liquid fraction

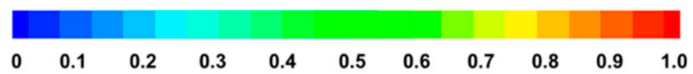

Figure 4. The liquid fraction distribution around the electro-thermal drilling probe (ETDP) for the case of heated probe tip temperature of $T_{\text {tip }}=368 \mathrm{~K}$ at time (a) $t=0 \mathrm{~s},(\mathbf{b}) t=30 \mathrm{~s}$, and (c) $t=60 \mathrm{~s}$. The enlarged fields of (d) liquid fraction within the green dotted box.

The ETDP slowly moves downward. The vertical positions of the heated probe tip, $z$, are $0,14.7$ and $29.8 \mathrm{~mm}$ at $t=0,30$ and $60 \mathrm{~s}$, respectively. We can calculate the ROP of ETDP from the expression of ROP $=d z / d t$. As a result, the ROP of ETDP, $d z / d t$, has a roughly constant value of $0.49 \mathrm{~mm} / \mathrm{s}$ for the case of $T_{\text {tip }}=368 \mathrm{~K}$.

Figure 5 represents the penetration depth of ETDP, $\Delta z$, for the different temperatures of the heated probe tip. The present study determines the penetration depth of ETDP, $\Delta z(t)$, from the following expression, $z(t)-z(0)$, as shown in the subset image of Figure 5. The evolution of the penetration depth of ETDP shows a linear tendency with time for all cases of $T_{\text {tip }}$. The ROP are $0.38,0.43$ and $0.49 \mathrm{~mm} / \mathrm{s}$ for the different $T_{\text {tip }}$ of 348,358 and $368 \mathrm{~K}$, respectively. According to Equation (10), the ROP of ETDP, $v$, is proportional with the heating power, $P$, where $P$ is the $\int_{0}^{R} q^{\prime}(r) \pi r^{2} d r$ and $q^{\prime}(r)$ indicates the local heat flux at the heated probe tip. Therefore, the fact that ROP has a constant value over time can be interpreted as that the heating power of ETDP also maintains a constant value during the drilling process. The ROP, $v$, increases with the temperature of the heated probe tip, $T_{\text {tip }}$, due to the increase of heating power, $P$. 


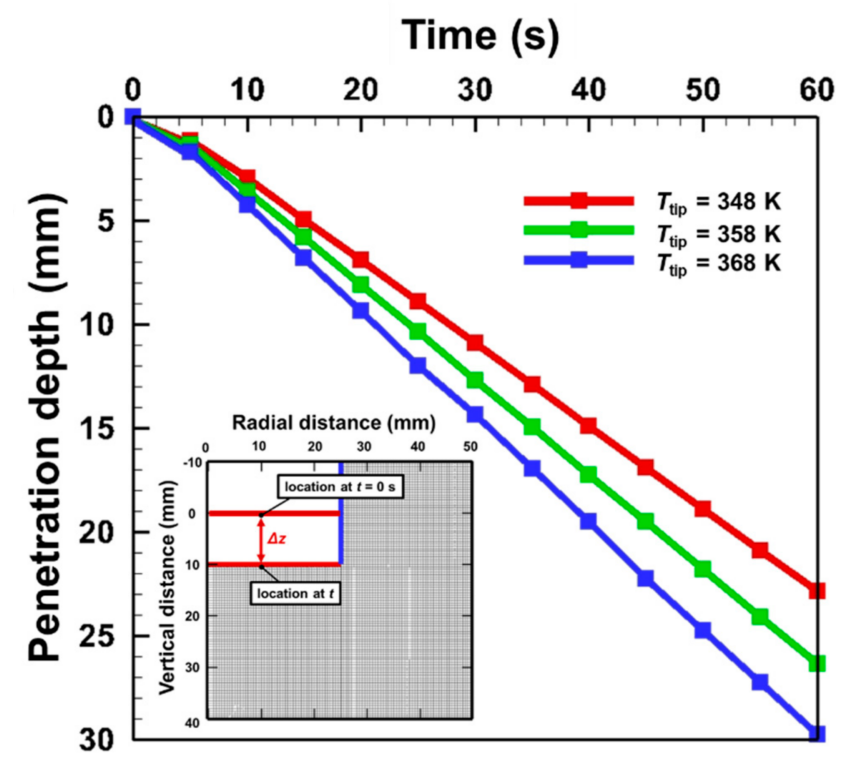

Figure 5. The penetration depth, $\Delta z$, for different heated probe tip temperatures, $T_{\text {tip }}$.

Figure 6a-c shows the evolution of heating power, $P(t)$, over time for the different $T_{\text {tip }}$. The evolution of heating power, $P(t)$, shows the fluctuation behavior, but its time-averaged values converge to $\left(P_{\text {avg }}=229.4 \mathrm{~W}, \sigma=23.1\right.$ for $\left.T_{\text {tip }}=348 \mathrm{~K}\right),\left(P_{\text {avg }}=264.2 \mathrm{~W}, \sigma=25.7\right.$ for $\left.T_{\text {tip }}=358 \mathrm{~K}\right)$, and $\left(P_{\text {avg }}=298.6 \mathrm{~W}, \sigma=28.4\right.$ for $\left.T_{\text {tip }}=368 \mathrm{~K}\right)$ where $\sigma$ is the standard deviation. The fluctuation behavior is from the results, the time-averaged heating power, $P_{\text {avg }}$, increases with the temperature of the heated probe tip. This is because the temperature difference between the mushy zone $(273.15 \mathrm{~K})$ and heated probe tip, $\Delta T=T_{\text {tip }}-273.15 \mathrm{~K}$, becomes higher with the increment of $T_{\text {tip }}$. The temperature differences are 75,85 and $95 \mathrm{~K}$.

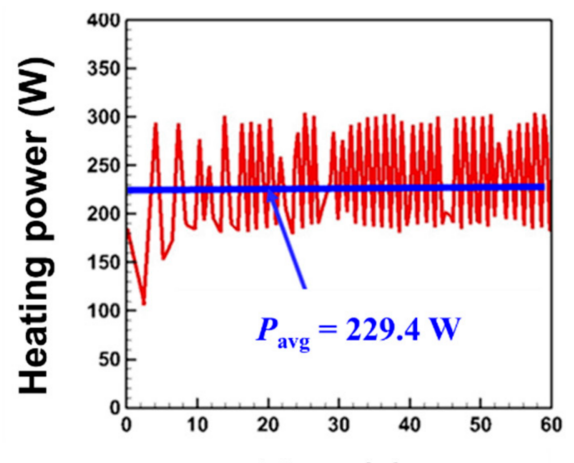

Time (s)

(a) $T_{\text {tip }}=348 \mathrm{~K}$

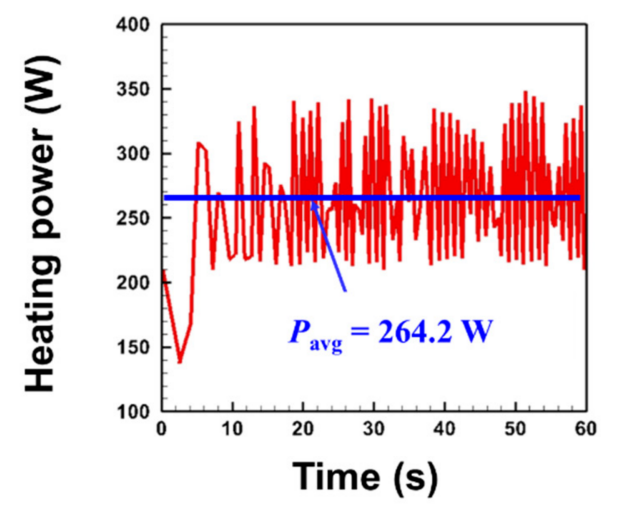

(b) $T_{\text {tip }}=358 \mathrm{~K}$

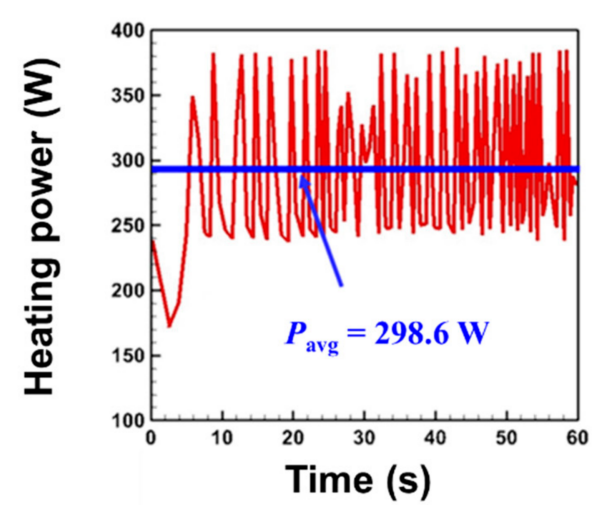

(c) $T_{\text {tip }}=368 \mathrm{~K}$

Figure 6. Comparison of heating power for different heated probe tip temperature of (a) $T_{\text {tip }}=348 \mathrm{~K}$, (b) $T_{\text {tip }}=358 \mathrm{~K}$ and (c) $T_{\text {tip }}=368 \mathrm{~K}$.

Therefore, the ROP increases with the temperature of the heated probe tip, $T_{t i p}$, due to the higher heating power. Figure $7 \mathrm{a}-\mathrm{c}$ represents the variations of ROP over time, predicted based on Equation (10). As a result, the time-averaged ROP, $v_{\text {avg }}$, converges to $(0.38 \mathrm{~mm} / \mathrm{s}$, $\sigma=0.02$ for $\left.T_{\text {tip }}=348 \mathrm{~K}\right),\left(0.43 \mathrm{~mm} / \mathrm{s}, \sigma=0.02\right.$ for $\left.T_{\text {tip }}=358 \mathrm{~K}\right)$, and $(0.49 \mathrm{~mm} / \mathrm{s}, \sigma=0.03$ for $\left.T_{\text {tip }}=368 \mathrm{~K}\right)$, respectively. The convergence of time-averaged ROP can be explained by that the time scale of the ROP of $10^{-3} \sim 10^{-4}$ is to with the time scale for thermal penetration, $k /\left(\rho c_{p} \delta\right)$, of $10^{-3}$ to $10^{-4}$, where $\delta$ is liquid layer thickness having an order between $10^{-4}$ to $10^{-3}(\mathrm{~m})[11]$. 


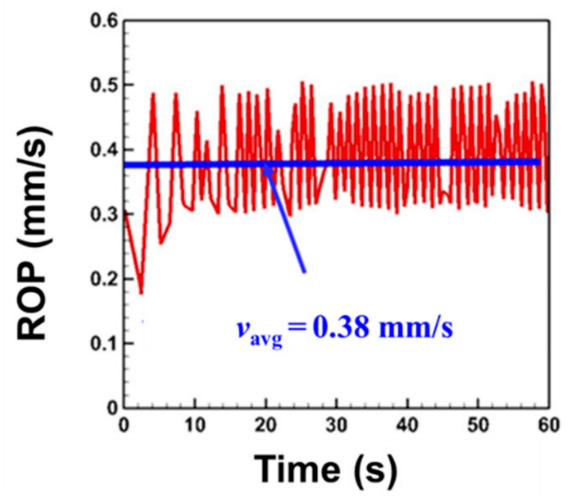

(a) $T_{\text {tip }}=\mathbf{3 4 8 ~ K}$

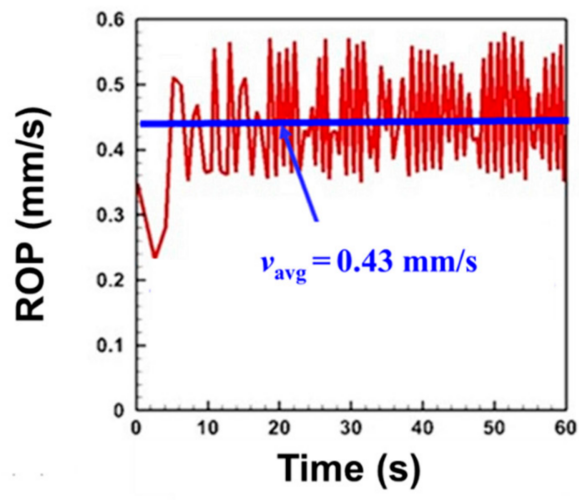

(b) $T_{\text {tip }}=358 \mathrm{~K}$

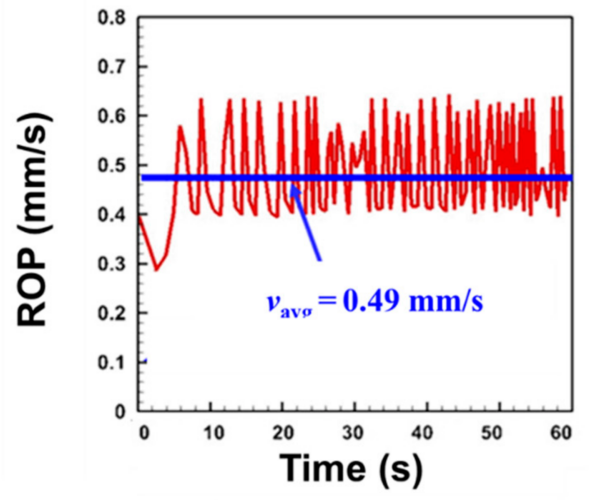

(c) $T_{\text {tip }}=368 \mathrm{~K}$

Figure 7. Comparison of rate of penetration (ROP) for different heated probe tip temperature of (a) $T_{\text {tip }}=348 \mathrm{~K}$, (b) $T_{\text {tip }}=358 \mathrm{~K}$ and (c) $T_{\text {tip }}=368 \mathrm{~K}$.

Figure 8 shows the evolution of liquid layer thickness for the different $T_{\text {tip }}$ over time. As above-mentioned, the initial thickness of the liquid layer is assumed to be $1 \mathrm{~mm}$ based on previous literature [11]. It continuously decreases to $0.618 \mathrm{~mm}$ for the $T_{\text {tip }}=348 \mathrm{~K}$, $0.623 \mathrm{~mm}$ for the $T_{\text {tip }}=358 \mathrm{~K}$, and $0.629 \mathrm{~mm}$ for the $T_{\text {tip }}=368 \mathrm{~K}$, at $60 \mathrm{~s}$. Although the ice directly contacts with the heated probe tip, the thickness of the liquid layer does not become thicker; rather, it becomes thinner. This is because the molten liquid layer is squeezed by the ETDP and pushed radially outward. In addition, the time scale of the ROP of $10^{-3}-10^{-4}$ has a similar order with the time scale of thermal penetration, $k /\left(\rho c_{p} \delta\right)$, of $10^{-3}$ to $10^{-4}$. Therefore, the liquid layer maintains its thickness within $1 \mathrm{~mm}$ during the drilling process, as shown in Figure 8.

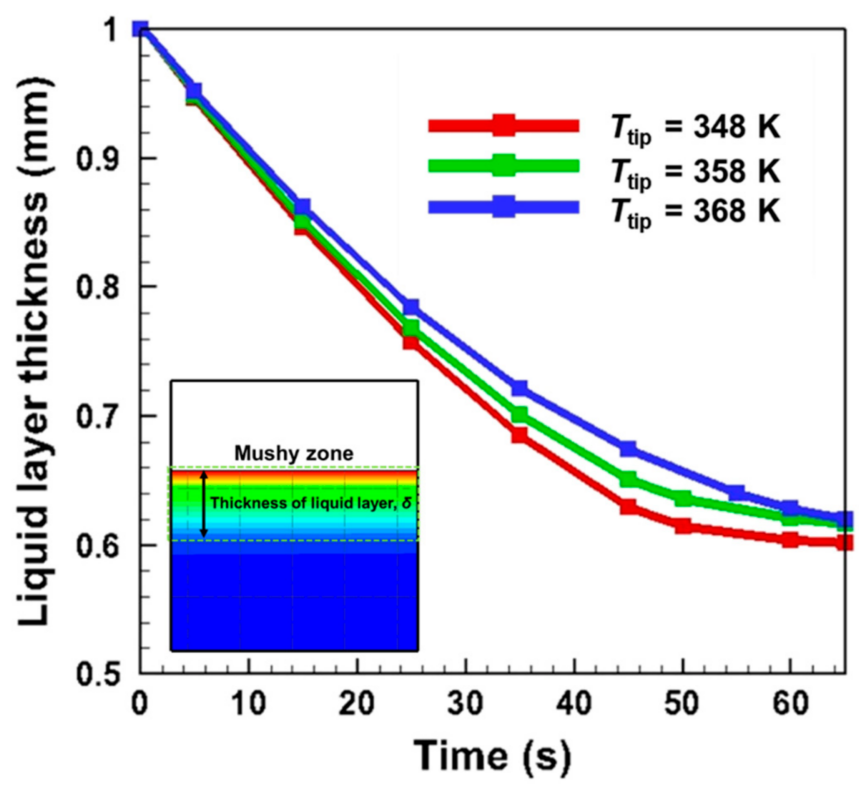

Figure 8. The evolution of liquid layer thickness for different heated probe tip temperatures of 348, 358 and $368 \mathrm{~K}$.

\section{Conclusions}

The present study performed a numerical analysis of the close-contact melting characteristics of electro-thermal drilling probe (ETDP) based on CFD simulations. From the numerical results, the influence of the temperature of heated probe tip on the formation of the molten thin liquid layer, and, subsequently, the rate of penetration (ROP) of ETDP were analyzed. In particular, the present study mimicked the transient movement of ETDP 
in a vertical direction using a simple model for predicting ROP. The distribution of temperature and liquid fraction were investigated during the drilling process. The following conclusions were drawn:

1. The mushy zone, where the melting process occurs, exists near the heated probe tip, and its temperature remains at a melting temperature of $273.15 \mathrm{~K}$. Although the temperature of the mushy zone has a constant value of $273.15 \mathrm{~K}$, its enthalpy increases during the melting process.

2. A thin liquid layer forms during the melting process, and the electro-thermal drilling probe can penetrate the ice by pushing and squeezing the molten thin liquid layer. The penetration depth linearly increases with time, and it implies that the ROP has a nearly constant value. The time-averaged ROP increases with the temperature of the heated probe tip, and has the values of $0.38,0.43$ and $0.49 \mathrm{~mm} / \mathrm{s}$ for the different heated probe tip temperatures of 348,358 and $368 \mathrm{~K}$, respectively.

3. The molten liquid layer maintains its thickness within the $1 \mathrm{~mm}$ around the heated probe tip. The thin liquid layer does not become thicker; instead, it stays at about $0.6 \mathrm{~mm}$ during the melting process. This is because the molten liquid layer is squeezed by the ETDP and pushed radially outward.

Author Contributions: Conceptualization, S.H.L. and K.K.; validation, K.K.; investigation U.-J.P., H.J.L. and C.H.J.; methodology H.S.K. and C.H.J.; simulation U.-J.P. and C.H.J.; supervision, S.H.L.; writing of the original draft U.-J.P. and C.H.J.; project administration, J.-Y.P. and S.H.L.; funding acquisition, J.-Y.P.; writing-review and editing S.H.L. and C.H.J. All authors have read and agreed to the published version of the manuscript.

Funding: This research was supported by a grant from the endowment project of "Development of core technologies of underwater robot ICT for polar under-ice-shelf exploration and remote monitoring" funded by the Korea Research Institute of Ships and Ocean Engineering (PES4010).

Acknowledgments: This research was supported by a grant from the endowment project of "Development of core technologies of underwater robot ICT for polar under-ice-shelf exploration and remote monitoring" funded by Korea Research Institute of Ships and Ocean Engineering (PES4010). This research was also supported by the Chung-Ang University Research Scholarship Grants in 2020.

Conflicts of Interest: The authors declare no conflict of interest.

\section{References}

1. Christner, B.C.; The WISSARD Science Team; Priscu, J.C.; Achberger, A.M.; Barbante, C.; Carter, S.P.; Christianson, K.; Michaud, A.B.; Mikucki, J.A.; Mitchell, A.C.; et al. A microbial ecosystem beneath the west antarctic ice sheet. Nature 2014, 512, 310-313. [CrossRef]

2. Rampelotto, P.H. Resistance of microorganisms to extreme environmental conditions and its contribution to astrobiology. Sustainability 2010, 2, 1602-1623. [CrossRef]

3. Priscu, J.C. Geomicrobiology of subglacial ice above lake vostok, antarctica. Science 1999, 286, 2141-2144. [CrossRef]

4. Talalay, P.G.; Zagorodnov, V.S.; Markov, A.N.; Sysoev, M.A.; Hong, J. Recoverable autonomous sonde (recas) for environmental exploration of antarctic subglacial lakes: General concept. Ann. Glaciol. 2014, 55, 23-30. [CrossRef]

5. Cuncil, N.R. Exploration of Antarctic Subglacial Aquatic Environments: Environmental and Scientific Stewardship; National Academic Press: Washington, DC, USA, 2007.

6. Kapitsa, A.P.; Ridley, J.K.; Robin, G.D.; Siegert, M.J.; Zotikov, I.A. A large deep freshwater lake beneath the ice of central east antarctica. Nature 1996, 381, 684-686. [CrossRef]

7. Zimmerman, W.; Bonitz, R.; Feldman, J. Cryobot: An ice penetrating robotic vehicle for mars and europa. In Proceedings of the Aerospace Conference Proceedings, Big Sky, MT, USA, 10-17 March 2001; pp. 311-323.

8. Kowalski, J.; Linder, P.; Zierke, S.; von Wulfen, B.; Clemens, J.; Konstantinidis, K.; Ameres, G.; Hoffmann, R.; Mikucki, J.; Tulaczyk, S.; et al. Navigation technology for exploration of glacier ice with maneuverable melting probes. Cold Reg. Sci. Technol. 2016, 123, 53-70. [CrossRef]

9. Aamot, H.W.C. Development of a vertically stabilized thermal probe for studies in and below ice sheets. J. Eng. Ind. 1970, 92, 263-268. [CrossRef]

10. Schuller, K.; Kowalski, J.; Raback, P. Curvilinear melting-a preliminary experimental and numerical study. Int. J. Heat Mass Transf. 2016, 92, 884-892. [CrossRef] 
11. Alemany, O.; Chappellaz, J.; Triest, J.; Calzas, M.; Cattani, O.; Chemin, J.; Desbois, Q.; Desbois, T.; Duphil, R.; Falourd, S.; et al. The subglacior drilling probe: Concept and design. Ann. Glaciol. 2014, 55, 233-242. [CrossRef]

12. Shreve, R.L. Theory of performance of isothermal solid-nose hotpoints boring in temperate ice. J. Glaciol. 1962, 4, 151-160. [CrossRef]

13. Talalay, P.G.; Li, Y.Z.; Sysoev, M.A.; Hong, J.L.; Li, X.; Fan, X.P. Thermal tips for ice hot-point drilling: Experiments and preliminary thermal modeling. Cold Reg. Sci. Technol. 2019, 160, 97-109. [CrossRef]

14. Suto, Y.; Saito, S.; Osada, K.-I.; Takahashi, H.; Motoyama, H.; Fujii, Y.; Tanaka, Y. Laboratory experiments and thermal calculations for the development of a next-generation glacier-ice exploration system: Development of an electro-thermal drilling device. Polar Sci. 2008, 2, 15-26. [CrossRef]

15. Treffer, M.; Komle, N.I.; Kargl, G.; Kaufmann, E.; Ulamec, S.; Biele, J.; Ivanov, A.; Funke, O. Preliminary studies concerning subsurface probes for the exploration of icy planetary bodies. Planet. Space Sci. 2006, 54, 621-634. [CrossRef]

16. Garcia-Diaz, M.; Pereiras, B.; Miguel-Gonzalez, C.; Rodriguez, L.; Fernandez-Oro, J. CFD analysis of the performance of a double decker turbine for wave energy conversion. Energies 2021, 14, 949. [CrossRef]

17. An, X.D.; Jiang, L.; Hassanipour, F. Numerical analysis of air vortex interaction with porous screen. Fluids 2021, 6, 70. [CrossRef]

18. Agrawal, K.K.; Misra, R.; Agrawal, G.D. CFD simulation study to evaluate the economic feasibility of backfilling materials for ground-air heat exchanger system. Geothermics 2021, 90, 102002. [CrossRef]

19. Di Renzo, A.; Napolitano, E.S.; Di Maio, F.P. Coarse-grain dem modelling in fluidized bed simulation: A review. Processes 2021, 9, 279. [CrossRef]

20. Voller, V.R.; Swaminathan, C.R. Eral source-based method for solidification phase change. Numer. Heat Transf. Part B Fundam. 1991, 19, 175-189. [CrossRef]

21. Voller, V.R.; Brent, A.D.; Prakash, C. The modeling of heat, mass and solute transport in solidification systems. Int. J. Heat Mass Transf. 1989, 32, 1719-1731. [CrossRef]

22. Voller, V.R.; Prakash, C. A fixed grid numerical modeling methodology for convection diffusion mushy region phase-change problems. Int. J. Heat Mass Transf. 1987, 30, 1709-1719. [CrossRef]

23. Voller, V.R. Modeling the unidirectional solidification of a binary alloy with the heat-balance integral method. J. Min. Met. Mater. Soc. 1987, 39, A13.

24. Kang, K.-G.; Ryou, H.-S. Computation of solidification and melting using the piso algorithm. Numer. Heat Transf. Part B Fundam. 2004, 46, 179-194. [CrossRef]

25. Lu, J.F.; Ding, J.; Yang, J.P. Solidification and melting behaviors and characteristics of molten salt in cold filling pipe. Int. J. Heat Mass Transf. 2010, 53, 1628-1635. [CrossRef]

26. Al-Maghalseh, M.M. Investigate the natural convection heat transfer in a pcm thermal storage system using ansys/fluent. Jordan J. Mech. Ind. Eng. 2017, 11, 217-223. 